\title{
Bile salt metabolism in tropical sprue
}

\author{
G. BEVAN 1 , R. ENGERT, F. A. KLIPSTEIN, N. MALDONADO, A. RUBUlis, \\ AND M. D. TURNER \\ From the Isaac Gordon Laboratory for Gastrointestinal Research, University of Rochester School of \\ Medicine and Dentistry, Rochester, New York, and the Tropical Malabsorption Unit of the Universities \\ of Rochester and Puerto Rico, San Juan, Puerto Rico
}

SUMMARY Mean and peak jejunal bile salt concentrations during digestion of a standard fat meal were found to be significantly lower in six Puerto Rican patients with untreated tropical sprue, all of whom had steatorrhoea, than in six asymptomatic subjects who had normal fat absorption. Bile salt pool size and turnover time did not differ significantly in the two groups.

It is suggested that bile salt concentrations may be reduced in the proximal small intestine of patients with tropical sprue as a result of excessive dilution by intestinal fluid. The finding of low bile salt concentrations in two asymptomatic subjects indicates that bile salt lack alone may not be sufficient to produce steatorrhoea.

Fat malabsorption in tropical sprue has usually been attributed to the histological changes in the jejunal mucosa. However, this concept may be an oversimplification of the events taking place during digestion in the upper small intestine in this condition.

A reduced micellar concentration of bile salts in the digestive area of the small intestine has now been firmly established as playing an important role in fat malabsorption and the various factors affecting jejunal bile salt concentrations have been extensively reviewed in several recent articles (Hofmann, 1967; Heaton, 1969; Dowling, 1972).

Two mechanisms by which the concentration of bile salts might be reduced are of potential importance in tropical sprue. First it has been shown that histological changes occur in the ileum as well as in the jejunum (Wheby, Swanson, and Bayless, 1971). Malabsorption of conjugated bile salt from the terminal ileum could lead to a reduced bile salt pool. Secondly, in some subjects there is an overgrowth of bacteria within the proximal small intestine (Gorbach, Banwell, Jacobs, Chatterjee, Mitra, Sen, and Mazumder, 1970). Deconjugation of bile salts has been shown to occur under these circumstances (Donaldson, 1965; Tabaqchali, Hat-

\footnotetext{
${ }^{1}$ Present address: Edgware General Hospital, Edgware, Middlesex, England

${ }^{1}$ Requests for reprints to Dr. G. Bevan, Edgware General Hospital, Edgware, Middlesex.

Received for publication 11 February 1974.
}

zioannou, and Booth, 1968) which, because of rapid absorption or precipitation of free bile acids, might result in inadequate micelle formation.

In order to assess the importance of bile salts in the pathogenesis of steatorrhoea in tropical sprue, jejunal bile salt concentrations during digestion were measured in six patients with untreated disease and in six asymptomatic subjects from the same population who had normal fat absorption.

\section{Materials and Methods}

\section{REAGENTS}

$3 \alpha$-Hydroxy-steroid dehydrogenase and NAD were obtained from Worthington Biochemical Corporation, Freehold, New Jersey, $24-{ }^{14} \mathrm{C}$-cholic acid from the New England Nuclear Corporation, Billericay, Massachusetts, and precoated silica gel thin-layer chromatography plates from Brinkman Instrument Corporation, Westbury, New York. All chemical reagents were of analytical grade or better. Liquid reagents other than sulphuric acid were redistilled before use.

\section{METHODS}

$3 \alpha$-Hydroxy-steroid dehydrogenase was prepared for use as previously described (Engert and Turner, 1973).

Cholecystokinin was a gift from Professor J. E. Jorpes and $\mathrm{Dr}$ V. Mutt, Karolinska Institute, Stockholm, Sweden. 
DETERMINATION OF BILE SALTS IN BILE AND INTESTINAL CONTENT

After extraction of bile or intestinal content with absolute ethanol, proteins were removed from the lipid mixture by saturated barium hydroxide. Fatty acids, triglycerides, and neutral steroids were removed in the heptane phase of an equilibrated mixture of $n$-heptane and $97.5 \%$ acetic acid. The final acetic acid phases were pooled, taken to dryness on a rotary evaporator, and dissolved in $5 \mathrm{ml}$ of methanol. The amount of bile salt in each residue was measured by a slightly modified version of the $3 \alpha$-hydroxy-steroid dehydrogenase method of Iwata and Yamasaki (1964). For determination of radioactivity, $0.2 \mathrm{ml}$ of the methanol solution was mixed in a scintillation vial with $15 \mathrm{ml}$ of a scintillation solution composed of toluene and ethylene glycol monomethyl ether $(2: 1 \mathrm{v} / \mathrm{v})$ containing $5.5 \mathrm{~g}$ diphenyloxazole (PPO) per litre. The radiation was measured in a Packard model 3330 Tri-Carb liquid scintillation counter. Quenching and efficiency of counting were determined so that the measured counts per minute (cpm) could be converted by calculation to disintegration per minute (dpm). The efficiency of the extraction procedure was calculated for each extract and was not found to alter significantly.

MEASUREMENT OF BILE SALT POOL SIZE AND TURNOVER RATE

In this study the radioactive tracer was given in the form of ${ }^{14} \mathrm{C}$-cholate. The specific activity data were then related to the total bile salt pool rather than to a single bile salt since the loss of label from a specific conjugate, eg, taurocholate, does not necessarily indicate excessive loss of bile salt but may result from biotransformation to another bile salt. Although representing changes occurring in several chemically distinct bile salt pools, the decay of specific activity was exponentially linear with time so it appeared to be a reasonable approximation to use the cholate label as a tracer for all three major bile salts comprising the total bile salt pool.

THIN-LAYER CHROMATOGRAPHY

In order to detect the presence of free bile acids, 20 $\mu l$ of the methanol extracts was chromatographed in two thin-layer chromatography systems: the acetic acid:CCL4:di-isopropyl ether:iso-amyl acetate:npropanol: benzene $(1: 4: 6: 8: 2: 2)$ mixture of Hofmann (1962), and the di-isopropyl ether:acetic acid:0.5 $\mathrm{N} \mathrm{H}_{2} \mathrm{SO}_{4}(11: 7: 2)$ mixture of McLeod and Wiggins (1968). The dried plates which had been run to within one inch of the top were sprayed with $30 \% \quad \mathrm{H}_{2} \mathrm{SO}_{4}$ and heated at $110^{\circ} \mathrm{C}$ until spots appeared.
GAS LIQUID CHROMATOGRAPHY

The proportions of the three major bile salts in the radioactive samples were measured in a gas chromatograph (Hewlett-Packard Model 402) after deconjugation of the salts with alkali and subsequent conversion to the t-butyl esters of the silylated compounds. Correction for the losses occurring during the deconjugation were made by measuring the recovery of a known amount of added labelled standard.

SMALL BOWEL BIOPSY

This was carried out using a Crosby capsule just beyond the duodeno-jejunal junction.

\section{PATIENTS STUDIED}

Two groups of subjects were studied (table I). The first group consisted of six patients with untreated tropical sprue presenting with a history of diarrhoea, anorexia, and weight loss. All had subnormal serum vitamin $\mathrm{B}_{12}$ levels and all had malabsorption of fat and xylose. Four had a megaloblastic anaemia and four had low serum folate concentrations. Jejunal biopsy showed subtotal villous atrophy in all six patients.

The second group comprised six asymptomatic Puerto Ricans selected at random from a large group of rural dwellers who were being surveyed at the time (Klipstein, Beauchamp, Corcino, Maldonado, Tomasini, Maldonado, Rubio, and Schenk, 1972). One of these subjects had reduced absorption of xylose. Two others had borderline values for vitamin $\mathbf{B}_{12}$ absorption but their serum vitamin $\mathbf{B}_{12}$ levels were normal. None had steatorrhoea. The small bowel morphology was normal in one asymptomatic subject but the remainder all showed some degree of villous atrophy.

After an overnight fast the upper jejunum was intubated with a radioopaque tube, the position of which was adjusted by fluoroscopy so that its aspiration port lay approximately 6 in beyond the ligament of Treitz. The subject then took a standard 'meal' of $50 \mathrm{ml}$ of corn oil in orange juice. The jejunal contents were aspirated continuously in individual 15-minute collection periods for one and $\mathrm{a}$ half to two hours. Five $\mathrm{ml}$ aliquots were removed from each of the 15-minute pools and the remaining material was reinjected down the tube at the conclusion of the aspiration period. Measurement of total bile salt concentration and thin-layer chromatography was carried out on each sample as described above.

Twenty-four to 48 hours later $5 \mu \mathrm{C}$ of $24-{ }^{14} \mathrm{C}$-cholate in sodium carbonate was injected intravenously. Bile samples were obtained at three, six, 24, 48, and 72 hours through a radioopaque tube positioned 


\begin{tabular}{|c|c|c|c|c|c|c|c|c|c|}
\hline \multirow[t]{4}{*}{ Patient No. } & \multirow{3}{*}{\multicolumn{2}{|c|}{$\begin{array}{ll}\text { Hb } & \text { Bone } \\
(\mathrm{g} / 100 \mathrm{ml}) & \text { Marro }\end{array}$}} & \multirow{3}{*}{$\begin{array}{l}\text { Serum } \\
\text { Folate } \\
(\mathrm{ng} / \mathrm{ml})\end{array}$} & \multirow{3}{*}{$\begin{array}{l}\text { Serum } \\
\text { Vitamin } B_{12} \\
(p g / m l)\end{array}$} & \multicolumn{2}{|c|}{ Xylose Absorption } & \multirow{3}{*}{$\begin{array}{l}\text { Faecal } \\
\text { Fat } \\
(g / 24 h r)\end{array}$} & \multirow{3}{*}{$\begin{array}{l}{ }^{87} \mathrm{CoB}_{18} \\
\text { Absorption } \\
\text { (\% oral dose) }\end{array}$} & \multirow{4}{*}{$\begin{array}{l}\text { Jejunal } \\
\text { Morphology } y^{2}\end{array}$} \\
\hline & & & & & $\begin{array}{l}\text { Urine } \\
\text { Excretion } \\
(\mathrm{g} / 5 \mathrm{hr})\end{array}$ & $\begin{array}{l}\text { Serum } \\
\text { Peak } \\
(\mathrm{mg} / 100 \mathrm{ml})\end{array}$ & & & \\
\hline & & & & & & & & & \\
\hline & $14-16$ & & $5-20$ & $150-900$ & 5 & $>30$ & $<6$ & $8-20$ & \\
\hline 1 & 5.0 & MA & $6 \cdot 2$ & 45 & $1 \cdot 0$ & 7 & $17 \cdot 8$ & 0 & 3 \\
\hline 2 & $8 \cdot 2$ & MA & $7 \cdot \overline{5}$ & 68 & $2 \cdot 2$ & 28 & $9 \cdot 2$ & $5 \cdot 3$ & 1 \\
\hline 3 & $14 \cdot 4$ & MA & $3 \cdot 6$ & 0 & $2 \cdot 3$ & 19 & $21 \cdot 4$ & $3 \cdot 6$ & 1 \\
\hline 4 & $11 \cdot 4$ & - & $3 \cdot 0$ & 75 & $2 \cdot 0$ & 16 & $10 \cdot 0$ & 0 & 2 \\
\hline 5 & $13 \cdot 4$ & - & $4 \cdot 4$ & 130 & $3 \cdot 2$ & 32 & $18 \cdot 8$ & $1 \cdot 7$ & 1 \\
\hline 6 & $10 \cdot 2$ & MA & $3 \cdot 1$ & 100 & $3 \cdot 4$ & 17 & $10 \cdot 0$ & 0 & 2 \\
\hline \multicolumn{10}{|c|}{ Asymptomatic Subjects } \\
\hline 7 & $12 \cdot 2$ & - & $8 \cdot 2$ & 360 & $2 \cdot 3$ & - & $4 \cdot 2$ & - & 2 \\
\hline 10 & $14 \cdot 0$ & - & 8.0 & 460 & $3 \cdot 8$ & 28 & $2 \cdot 6$ & $22 \cdot 0$ & 1 \\
\hline 11 & 9.0 & - & $20 \cdot 0$ & 550 & $9 \cdot 8$ & 41 & $3 \cdot 1$ & $7 \cdot 5$ & 1 \\
\hline 12 & $15 \cdot 2$ & - & $5 \cdot 5$ & 290 & $5 \cdot 7$ & 54 & $1 \cdot 7$ & 6.6 & 2 \\
\hline
\end{tabular}

Table I Results of laboratory investigations

${ }^{1} \mathrm{MA}$ indicates megaloblastic changes in the bone marrow. ${ }^{2} 0=$ normal, $4=$ total villous atrophy

fluoroscopically in the third portion of the duodenum after the intravenous administration of $\mathbf{4 0}$ dog units of cholecystokinin. As much bile as possible was obtained each time. This was mixed thoroughly, a $4 \mathrm{ml}$ aliquot removed, and the remainder returned to the duodenum through the tube in order to avoid reducing the total bile salt pool. The specific radioactivity and the concentration of the individual bile salts were determined in each sample. The proportions of the three major bile salts in the bile samples obtained following gallbladder stimulation at six and 72 hours after the injection of ${ }^{14} \mathrm{C}$-cholate were determined by gas liquid chromatography as outlined above. These samples were also examined by thin-layer chromatography.

\section{Results}

BILE SALT CONCENTRATIONS

The mean bile salt concentrations of the duodenal aspirates collected during the two-hour period after ingestion of the standard meal averaged 2.4 mmoles per litre in the six persons with untreated tropical sprue; this value was significantly lower $(P<0.001)$ than the average of the mean concentrations of bile salt in the aspirates from the asymptomatic subjects which averaged 11.9 mmoles per litre (table II). In each of the untreated patients, all of whom had steatorrhoea, the mean bile salt concentrations during digestion were less than 5 mmoles per litre whereas in only two of the asymptomatic subjects were the

\begin{tabular}{|c|c|c|c|c|c|}
\hline \multirow[t]{2}{*}{ Patient No. } & \multicolumn{2}{|c|}{$\begin{array}{l}\text { Bile Salt Concentration during Digestion } \\
\text { (mMoles } / \text { l) }\end{array}$} & \multirow[t]{2}{*}{$\begin{array}{l}\text { Bile Salt Pool } \\
\text { (mMoles) }\end{array}$} & \multirow[t]{2}{*}{$T 1 / 2(h r)$} & \multirow[t]{2}{*}{$\begin{array}{l}\text { Bile Salt Turnover } \\
(\mu M \text { Moles } / h r)\end{array}$} \\
\hline & Peak & Mean & & & \\
\hline \multicolumn{6}{|c|}{ Untreated Tropical Sprue Patients } \\
\hline 1 & 1.60 & 0.72 & $2 \cdot 5$ & 44 & 28 \\
\hline 2 & $5 \cdot 13$ & 3.34 & $3 \cdot 3$ & 44 & 38 \\
\hline$\overline{3}$ & 6.03 & 2.00 & $10 \cdot 0$ & 49 & 102 \\
\hline 4 & $3 \cdot 64$ & 1.89 & 8.5 & 36 & 118 \\
\hline 5 & 6.09 & $2 \cdot 27$ & 5.9 & 27 & 110 \\
\hline & $10 \cdot 11$ & $4 \cdot 39$ & $7 \cdot 3$ & 76 & 48 \\
\hline \multicolumn{6}{|c|}{ Asymptomatic Subjects } \\
\hline 7 & 3.61 & 1.76 & $5 \cdot 0$ & 40 & 62 \\
\hline 8 & $2 \cdot 85$ & 1.50 & $5 \cdot 2$ & 31 & 84 \\
\hline 9 & $22 \cdot 9$ & 12.5 & 8.9 & 38 & 117 \\
\hline 10 & $54 \cdot 4$ & $25 \cdot 2$ & $10 \cdot 5$ & 160 & 33 \\
\hline 11 & $19 \cdot 8$ & $17 \cdot 1$ & $11 \cdot 3$ & 81 & 70 \\
\hline 12 & 24.9 & $13 \cdot 4$ & $5 \cdot 3$ & 49 & 56 \\
\hline
\end{tabular}

Table II Results of bile salt determinations 
mean concentrations below this level (fig 1). The peak concentration of bile salt in the sprue patients during digestion averaged 5.4 mmoles per litre. This value was significantly lower $(P<0.001)$ than the average of the peak concentrations in the asymptomatic subjects which was 21.4 mmoles per litre (table II). Peak values exceeded 5 mmoles per litre at some time during the digestion period in four of the sprue patients.

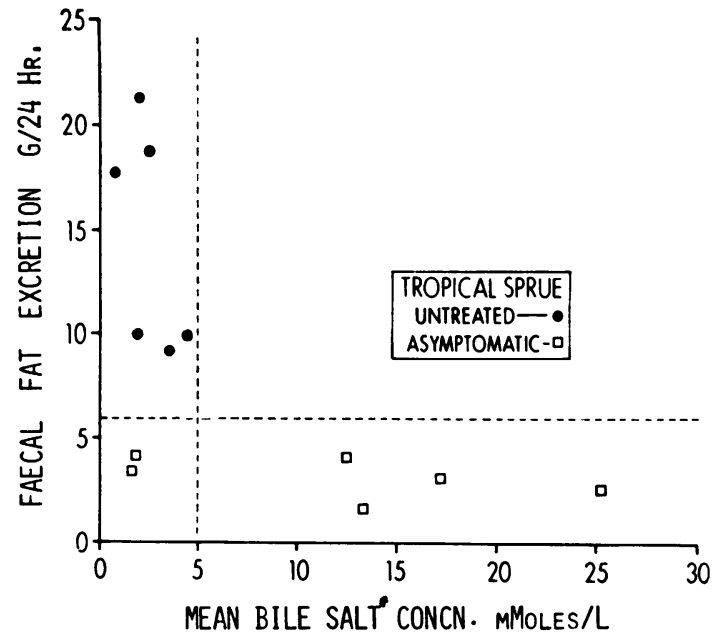

Fig Relationship of mean bile salt concentration to faecal fat excretion.

BILE SALT POOL SIZE AND TURNOVER RATE The size of the total bile salt pool averaged 6.2 mmoles in the six untreated patients with tropical sprue and 7.7 mmoles in the asymptomatic subjects (table II). Analysis of the pool size measurements in these two groups by the Student $t$ test indicated that this difference was not significant.

The mean half-time for the bile salt pool was 49 $\mathrm{hr}$ in the patients with untreated tropical sprue and $66 \mathrm{hr}$ in the asymptomatic subjects (table II). Turnover rate for the bile salt pools averaged 74 $\mu$ moles per hour in the untreated sprue patients and $70 \mu$ moles per hour in the asymptomatic subjects. The differences in the half-times and turnover rates of the ${ }^{14} \mathrm{C}$-cholic acid pool in these two groups were not statistically significant. The values obtained were similar to those previously reported in normal subjects (Linstedt, 1957; Danielsson, Eneroth, Hellstrom, Linstedt, and Sjövall, 1963).

Relatively little change was seen in the proportion of the three major bile acids in the bile specimens obtained at six and $72 \mathrm{hr}$ in four patients with untreated tropical sprue tested (table III).

THIN-LAYER CHROMATOGRAPHY

In only one sample of all jejunal and duodenal aspirates was there evidence of the presence of unconjugated bile acid. A small amount of deoxycholic acid was found in one aspirate from patient 1 . From the known sensitivity of the methods employed, it is possible to conclude that in the patients with tropical sprue less than $1 \%$ of the bile acids in the upper jejunum or duodenum were present in the unconjugated form.

\section{Discussion}

The bile salt concentrations during digestion in the asymptomatic Puerto Ricans showed the same marked variation from sample to sample that has been observed in normal European subjects (Dawson, 1971) and the mean bile salt concentrations in the asymptomatic Puerto Ricans were similar to those seen in these normal subjects. There was, therefore, no evidence to suggest that the asymptomatic Puerto Ricans were any different from normal Europeans in this regard. Furthermore, the mild structural and functional intestinal changes found in five of the six asymptomatic Puerto Ricans were not considered unusual since these subjects were randomly selected from a population one half of whom have such changes (Klipstein et al, 1972).

Both the peak and mean bile salt concentrations during digestion were significantly lower in the subjects with tropical sprue than in the asymptomatic

\begin{tabular}{|c|c|c|c|c|c|c|}
\hline \multirow[t]{2}{*}{ Patient No. } & \multicolumn{3}{|c|}{ Six Hours } & \multicolumn{3}{|c|}{72 Hours } \\
\hline & $\begin{array}{l}\text { Cholate } \\
(\%)\end{array}$ & $\begin{array}{l}\text { Deoxycholate } \\
(\%)\end{array}$ & $\begin{array}{l}\text { Chenodeoxycholate } \\
(\%)\end{array}$ & $\begin{array}{l}\text { Cholate } \\
(\%)\end{array}$ & $\begin{array}{l}\text { Deoxycholate } \\
(\%)\end{array}$ & $\begin{array}{l}\text { Chenodeoxycholate } \\
(\%)\end{array}$ \\
\hline $\begin{array}{l}2 \\
3 \\
4 \\
5\end{array}$ & $\begin{array}{l}51 \cdot 7 \\
61 \cdot 7 \\
33 \cdot 8 \\
39 \cdot 5\end{array}$ & $\begin{array}{r}18 \cdot 7 \\
7 \cdot 6 \\
12 \cdot 2 \\
33.9\end{array}$ & $\begin{array}{l}29 \cdot 6 \\
30 \cdot 7 \\
54 \\
26.6\end{array}$ & $\begin{array}{l}52 \cdot 4 \\
57 \cdot 4 \\
39 \cdot 3 \\
29 \cdot 3\end{array}$ & $\begin{array}{l}21 \cdot 1 \\
17 \cdot 2 \\
10 \cdot 8 \\
49 \cdot 2\end{array}$ & $\begin{array}{l}20.5 \\
25 \cdot 4 \\
49.9 \\
21.5\end{array}$ \\
\hline
\end{tabular}

Table III Composition of bile specimens at six and 72 hours after $24-{ }^{14} C$-cholate 
controls. The mean value was lower than that reported in three patients with tropical sprue studied by Cassells and his colleagues (Cassells, Banwell, Gorbach, Mitra, and Mazumder, 1970). All patients with steatorrhoea had mean bile salt concentrations below 5 mmoles per litre during digestion (see fig). At this concentration the amount of lipid in the micellar phase is severely restricted (Van Deest, Fordtran, Morawski, and Wilson, 1968) so that fat absorption is likely to be impaired. However, two other subjects who also had low mean levels of bile salt did not have steatorrhoea (see fig). This suggests that a low bile salt concentration is not the only factor responsible for steatorrhoea in tropical sprue and a combination of factors such as low bile salt concentration, impaired mucosal function, and possible pancreatic insufficiency may be necessary to cause malabsorption of fat.

Unconjugated bile acids were detected in only one sample of jejunal fluid from all the patients tested so that appreciable deconjugation of bile salts did not appear to be taking place in these patients. This finding is similar to that previously reported by others (Nair, Banwell, Gorbach, Lilis, and Alcaraz, 1970; Kapadia, Radhakrishnan, Mathan, and Baker, 1971). Deconjugated bile salts may be transported rapidly across the upper small gut mucosa so that the failure to detect free bile acids in the jejunal content does not absolutely exclude the occurrence of some deconjugation. However, deconjugation of bile salt in the proximal small intestine requires the presence of anaerobic organisms under conditions of stasis (Gorbach and Tabaqchali, 1969). In patients with tropical sprue the bacterial flora of the upper small intestine has been found to consist chiefly of aerobic organisms (Gorbach et al, 1970).

The mean bile salt pool was not significantly reduced in the subjects with tropical sprue as compared to the asymptomatic group. The mean halftime for the bile salt pool in the untreated sprue patients was somewhat shorter than has been reported in normal subjects (Lindstedt, 1957), but considerably longer than values found in subjects after total ileectomy (Hofmann, 1967). It is, therefore, apparent that subjects with tropical sprue, despite an ileal lesion as evidenced by malabsorption of vitamin $B_{12}$, do not lose large quantities of bile salt from ileal malabsorption.

It seems unlikely that sluggish contraction of the gallbladder in response to corn oil stimulation accounts for the reduced bile salt concentrations noted during absorption. A subnormal response of the gallbladder has been described in patients with coeliac disease (Low-Beer, Heaton, and Read,1970), and this remains to be evaluated in tropical sprue, but in contrast to the shortened half-time of the bile salt pool demonstrated in our patients with tropical sprue, the sluggish gallbladder response in subjects with coeliac disease is associated with a prolonged bile salt half-time.

Patients with tropical sprue have been found to be in an active secretory state for water and electrolytes (Banwell, Gorbach, Mitra, Cassells, Mazumder, Thomas, and Yardley, 1970; Corcino, Maldonado, and Klipstein, 1972). It seems possible that the reduced bile salt concentrations during absorption in the presence of a normal bile salt pool size could be the result of excessive dilution of the bile salts within the proximal jejunum due to increased fluid secretion into the lumen.

The authors thank Dr Angel Cintron-Rivera, University of Puerto Rico, for his kind cooperation and Miss Milagros Maldonado, RN, and her staff at the Clinical Research Centre for their assistance in conducting the clinical investigations.

Supported by grants from the Research Corporation, New York, the Wellcome Trust, London, England, grant 5-TO-1AM-05177 from the National Institute of Arthritis and Metabolic Disease, Bethesda, Maryland, and grant RR-63-09 from the General Clinical Research Centre Program of the Division of Research Resources, US Public Health Service.

\section{References}

Banwell, J. G., Gorbach, S. L., Mitra, R., Cassells, J. S., Mazumder, D. N. G., Thomas, J., and Yardley, J. H. (1970). Tropical sprue and malnutrition in West Bengal. II. Fluid and electrolyte transport in the small intestine. Amer. J. clin. Nutr., 23, 1559-1568.

Cassells, J. S., Banwell, J. G., Gorbach, S. L., Mitra, R., and Mazumder, D. N. G. (1970). Tropical sprue and malnutrition in West Bengal. IV. Bile salt deconjugation in tropical sprue. Amer. $J$. clin. Nutr., 23, 1579-1581.

Corcino, J. J., Maldonado, M., and Klipstein, F. A. (1972). Effect of glucose on jejunal transport of water and electrolytes in tropical sprue. Clin. Res., 20, 450.

Danielsson, H., Eneroth, P., Hellstrom, K., Linstedt, S., and Sjövall, J. (1963). On the turnover and excretory products of cholic and chenodeoxycholic acid in man. J. biol. Chem., 238, 22992304.

Dawson, A. M. (1971). The absorption of fat. J. clin. Path., 24, Suppl. (Roy. Coll. Path.) 5, 77-84.

Donaldson, R. M., Jr. (1965). Studies on the pathogenesis of steatorrhoea in the blind loop syndrome. J. clin. Invest., 44, 1815-1825.

Dowling, R.H.(1972). The enterohepatic circulation. Gastroenterology, 62, 122-140.

Engert, R., and Turner, M. D. (1973). Problems in the measurement of bile acids with 3- $\alpha$-hydroxysteroid dehydrogenase. Analyt. Biochem., 51, 399-407.

Gorbach, S. L., Banwell, J. G., Jacobs, B., Chatterjee, B. D., Mitra, R., Sen, N. N., and Mazumder, D. N. G. (1970). Tropical sprue and malnutrition in West Bengal. I. Intestinal microflora and absorption. Amer. J. clin. Nutr., 23, 1545-1558.

Gorbach, S. L., and Tabaqchali, S (1969). Bacteria, bile, and the small bowel. Gut, 10, 963-972.

Heaton, K. W. (1969). The importance of keeping bile salts in their place. Gut, 10, 857-863.

Hofmann, A. F. (1962). Thin-layer absorption chromatography of 
free and conjugated bile acids on silicic acid. J. Lipid Res., 3, 127-128.

Hofmann, A. F. (1967). The syndrome of ileal disease and the broken enterohepatic circulation: cholerheic enteropathy. Gastroenterology, 52, 752-757.

Iwata, T., and Yamasaki, K. (1964). Enzymatic determination and thin layer chromatography of bile acids in the blood. $J$. Biochem. (Tokyo), 56, 424-431.

Kapadia, C. R., Radhakrishnan, A. N., Mathan, V. I., and Baker, S. J. (1971). Studies on bile salt deconjugation in patients with tropical sprue. Scand. J. Gastroent., 6, 29-31.

Klipstein, F. A. (1968). Progress in gastroenterology: tropical sprue. Gastroenterology, 54, 275-293.

Klipstein, F. A., Beauchamp, I., Corcino, J. J., Maldonado, M., Tomasini, J. T., Maldonado, N., Rubio, C., and Schenk, E. A. (1972). Nutritional status and intestinal function among rural populations of the West Indies. II. Barrio Nuevo, Puerto Rico. Gastroenterology, 63, 758-767.

Linstedt, S. (1957). The turnover of cholic acid in man: bile acids and steroids. Acta Physiol scand., 40, 1-9.

Low-Beer, T. S., Heaton, K. W., and Read, A. E. (1970). Gallbladder inertia in adult coeliac disease. Gut, 11, 1057-1058.

McLeod, G. M., and Wiggins, H. S. (1968). Bile salts in small intestinal contents after ileal resection and in other malabsorption syndromes. Lancet, 1, 873-876.

Nair, P. P., Banwell, J. G., Gorbach, S. L., Lilis, C., and Alcaraz, A. (1970). Tropical sprue and malnutrition in West Bengal. III. Biochemical characteristics of bile salts in the small intestine. Amer. J. clin. Nutr., 23, 1569-1578.

Tabaqchali, S., Hatzioannou, J., and Booth, C. C. (1968). Bile-salt deconjugation and steatorrhoea in patients with the stagnantloop syndrome. Lancet, 2, 12-16.

Van Deest, B. W., Fordtran, J. S., Morawski, S. G., and Wilson, J. D. (1968). Bile salt and micellar fat concentration in proximal small bowel contents of ileectomy patients. J. clin. Invest., 47, 1314-1324.

Wheby, M. S., Swanson, V. L., and Bayless, T. M. (1971). Comparison of ileal and jejunal biopsies in tropical sprue. Amer. J. clin. Nutr., 24, 117-123. 